\title{
Prescriptive Aspects of the Descriptive Translation Studies
}

\author{
Kunlun $\mathrm{Liu}^{1}$ \\ ${ }^{1}$ School of Foreign Languages, China Normal University, China \\ Correspondence: Kunlun Liu, No.1 Shida Road, Nanchong 637000, Sichuan, China. Tel: 86-817-256-8972. \\ E-mail: 1k1688@hotmail.com
}

Received: March 30, 2014 Accepted: May 9, 2014 Online Published: July 29, 2014

doi: 10.5539/ijel.v4n4p13

URL: http://dx.doi.org/10.5539/ijel.v4n4p13

\begin{abstract}
Toury's DTS has been playing a significant role in translation studies since the 1980s and it targets at establishing a general theory of translation, which is claimed to have quite different properties from those of traditional translation theories: pure objectiveness and descriptiveness. However, the descriptiveness of this theory is not so convincing as expected. On the contrary, its prescriptiveness is prevailing and deep rooted when closely examined. This thesis is intended to expose the descriptiveness of the theory and the thinking lines underlying it through critically analyzing several key concepts so important in this theory that they are virtually its backbone. This method involves checking Toury's personal interpretation of Holmes' great scheme of translation studies, the norm theory and translation laws. In this way one can clearly see that Toury's theory has been heavily influenced by Russian Formalism and traditional translation paradigms.

The thesis does not stop at discussing the prescriptiveness of Toury's translation theory. The above discussion triggers out other ones which shall be handled with equal importance in this thesis, including the dialectical relationships of prescription and description, and translation theory and practice. Therefore, the main focus in this thesis is extended from the particular to the general. This extension is natural in that it helps to enhance rethinking the evaluation of prescription: its value and function in theoretical learning, and discussions should not be ignored or lessened for the reason that some existent problems in present translation teaching should be faced up to and addressed timely.
\end{abstract}

Keywords: DTS, descriptiveness, formalism, translation norms, translational laws

\section{Introduction}

The intention of this study is to explore the prescriptive aspects of the Descriptive Translation Studies by Gideon Toury and to re-examine and re-evaluate the so-called prescriptive theories or models.

Since the early 20th century, translation studies gradually broke away from the marginal status within other related disciplines and established itself as an empirical science. From then on, schools of thought have kept coming out and each claims its legitimacy for existence. Among these schools is Descriptive Translation Studies (DTS). In the 1980s, DTS was favored by most researchers in this field. This model encourages them to concentrate on descriptive work rather than on theoretical constructing. Few query its theoretical footings.

Toury's treatise Descriptive Translation Studies and Beyond (1995) thoroughly develops the descriptive branch of Holmes" "Map" and can be regarded as a revised edition of his previous monograph In Search of a Theory of Translation (1980). He found fault with existing source-oriented theoretical models of translation, proposed Norms as a key to examining and describing the socio-cultural conditioning factors on the part of the translator and generalized a series of laws which he thought govern the production of translated texts. He clearly differs himself from the so-called traditional translation paradigms and aims to "search" a general theory of translation totally localized in the target environment. To a large degree his model stimulates a number of researchers to focus on descriptive work rather than continue to be overwhelmed and puzzled in "theory" in the 1980s. Yet, no matter how strongly he desires to distance himself from the traditional models, the prescriptive ones, he does not succeed in steering a completely new course and cut a clear line between prescription and description. As it were, ha starts up descriptively, but ends up prescriptively. A large circle has been drawn before he knows it.

However, at the turn of this century, DTS began to be encountered with questionings from influential scholars in the discipline. Among them are Edward Gentzler and Theo Hermans. The reading of their works inspires this thesis. 
But their critical writing only points out the potential prescription of Toury's theory without its being fully followed-up. This thesis is supposed to take up what they have left. A re-reading of several key concepts, such as Norms, Tertium Comparationis and Translational Laws, promises to point to his prescriptive foundation. Even though Toury himself claims that he has never got along well with traditional theories, the prescriptive and source-oriented ones, he never finds a way out. Rather, he has no alternatives. Prescription and description, like twins, cannot be separated no matter how often prescription is discriminated and description is privileged (which is also true with modern linguistics).

A discussion of the relationship of theory and practice is also essential to this thesis as it illustrates how discriminating views of prescription can be reevaluated. The current situation calls for more prescriptive theories so as to provide sufficient guidelines for those in need, like inexperienced translation practitioners.

\section{Revisiting Toury's Theory}

Gideon Toury's contribution to translation studies can be seen clearly through his large quantity of writings on this subject: more than 70 articles, 30 book reviews, 10 books and dictionaries (edited or co-edited) and 3 monographs on Translation Studies, among which Descriptive Translation Studies and Beyond (1995) is much more read than others. According to Gentzler (2001, pp. 123-124), Toury's work can be divided into two periods: first, 1972-1976, collaborated with Even-Zohar on Polysystem and involved a comprehensive sociological study of the cultural conditions affecting the translation of foreign language novels into Hebrew, the work of this period reported in Translation Norms and Literary Translation into Hebrew (1977); second, 1975-1980, an attempt to develop a more comprehensive theory of translation based on findings from his field study, summarized in In Search of a Theory of Translation (1980). Gentzler's review includes Toury's main efforts or the prime time when his acknowledged theoretical strength developed and “finalized". However, Toury's research continues, if the 1995 book is indicative of something, even though two influential figures in this discipline, Gentzler (2001) and Hermans (1999) claim they have seen nothing new in it.

On more than one occasion Toury voiced his strong opposition to traditional translation theories. The traditional only exists as a starting point to distinguish his own model. What were once hailed as the merits of the traditional paradigms are now the very object targeted at by the new model. The prominent distinction lies in the source-oriented approaches the traditional theories generate. On the one hand, in the old paradigms, the main focus is placed on the original text and author, hence a heavy emphasis on "faithfulness". The translator is confined to what the original has predestined and no distortion of the intent of the original is allowed. This is what the "invariant" means. Its philological basis attaches much importance to linguistic and idealistic "isomorphism". In terms of languages, Chomsky's deep-structure hypothesis enhances the belief that there exist universals which underlie all the forms of languages all over the world and the signified comprises everything which is common to all the speakers. As language and thought are interwoven, what is thought of and expressed in one language can be surely put across to another. However, this is where Toury started undermining the philological footings of the early translation models. He sees intrinsic heterogeneity across languages and cultures. Nothing in the original can be transferred without any loss in the receiving context. On the other hand, traditional theories prescribe certain set of criteria to judge the translation product in terms of "correctness" or "appropriateness" regardless of the acceptance in the target culture. In Toury's terminology, only "adequate" translation is valued (Toury, 1995, pp. 53-69). In view of all that discussed above, Toury was determined to invert the viewpoint and construct a target-oriented model to steer a course he sees compatible to translation studies.

Toury's aim to draw a clear line from the traditional paradigms is far from realized. As Lieven D'hulst (quoted in Hermans, 1999, pp. 98-99) points out that the history of translation theory matters and our current thinking stems from it, the past paradigms do not necessarily become irrelevance. The symbolic term "equivalence" for the traditional models is still seen now and then in Toury's reasoning. This term was not as "hollowed" as other scholars thought to be. Another index of his close connection to the traditional theories is his insistence on employing a concept "Tertium Comparationis" as the invariance to conduct translational and literary comparisons. This concept is not different in essence from the so-called "obsolete" equivalence. There is no entity like "Tertium Comparationis" that exists between the source and the translation. It is reasonable to regard this as one of his predictions more than as his construction or hypothesis just for the sake of comparison itself. Toury holds that translation always tends to be an "interlanguage", adjacent but never identical to the source and the translation (Gentzler, 2001, pp. 128-130). This interlanguage cannot linger in some kind of vacuum. Conception of this sort is no different from the deep structure theorizing either. It illustrates that Toury did not really divorce from the traditional translation paradigms from the very start. 


\section{Toury's Prescriptiveness All the Way}

Toury set out not to be prescriptive when he started establishing a completely new model to handle what the traditional theories were incapable of, a model claimed to be explanatory and predictive, totally descriptive and objective. As a translation practitioner and then a translation researcher and a literary scholar, he was very familiar with various schools of translation theories and literary theories. These theories inspired as well as confined his thinking. The influences cannot be underestimated when his finally matured model is considered in terms of description as weighed against prescription underlined. One of the influences comes from the Russian Formalism.

\subsection{The Influence of Russian Formalism}

Many modern theories in literature and translation can be traced back to Russian Formalism. In fact, this literary movement prevailing in Russia in the beginning of the last century took too much responsibility. Even-Zohar's system theory took direct inspiration from it to a point of borrowing the key term "system" without much change, even though Even-Zohar himself added "poly-" to "system" with some sense of being deliberately mystifying. As an active scholar in the systemic paradigm, Toury's thinking was heavily influenced by Russian Formalism and then by Even-Zohar's systemic theory.

Russian Formalism placed stress on such things as literary devices, "literariness", and "defamiliarization”. The formalists deemed literature as totally autonomous entity, within which literary evolutions did not bear on anything beyond its boundaries as it was unaffected by the society or the culture. This idealistic thinking was presumably related to the Russian reality at that time with the highly centralized censorship imposed on literature, which was seen to be detrimental to literary development. This reality gave birth to Formalism, which prescribed that literature should develop at a certain direction. The scholars involved were intent to conceive literary policies to safeguard literature's "literariness". The essential point here is that they were self satisfactory with what they intended or helped to create: a realm in which they thought they would be free. Although Russian Formalism took on a new complexion as Tynjanov $(1927,1928)$ initiated to break the literary "ivory tower" to care about the reality, the society and to introduce a premature systemic position to theorize literary evolution, the prescriptive nature remained as before and this hugely influenced the followers, as we can see in Even-Zohar's literary "universals" and Toury's translational "laws", both of whom refused to made important alterations to their theory or model throughout the years.

As Gentzler (2001) noted that “As advanced as Tynjanov's model was, the purported diachronic, evolutionary model still was primarily determined by his synchronic conceptual predisposition”, even Tynjanov himself had not succeeded in completely branching out from the fetters the immanent Formalist thinking imposed on those obsessed in the literary theory, let alone the latter Formalists including Holmes, Even-Zohar, and Toury, all of whom absorbed Formalism largely from Tynjanov. What matters is not what Formalism claimed to revolutionize literary history, but the thinking lines which prompt advocates to restrict their mind to a designated position. They would construct their own stronghold, and prescribe order and law to safeguard it. They would take it as an autonomous region which was conceived as self-sufficient, where all things worked out perfectly within, not contaminated by the reality or the material world from outside. Theirs are high-brow undertakings which follow particular conventions and those conventions are deliberately constituted by themselves to maintain the (literary) order. They prescribed and they were self-satisfied.

Strongly influenced by Russian Formalism, Even-Zohar regarded literature as a complex and dynamic system rather than a static collection of independent texts. According to this framework all texts within a given literature enter into a permanent struggle for domination. Translated literature is only one of the elements in this battle. It is necessary to include translated literature in the polysystem (Even-Zohar, 1993). Translational comparisons between one source text and its translation become less dominant in this context. Corpus projects of various kinds are encouraged because they facilitate comparisons of series of texts or translation problems, for example, of several translations of one source, different stages in the translation of a text, entire production of individual translators or scholar of translators, and above all translations of corpora of TL originals. This approach allows room for micro-level textual studies. It also throws light on the significance of macro level sociological expansion of the field.

His colleague and collaborator Gideon Toury refers to translations as facts of target cultures; on occasions facts of a special status, some times even constituting identifiable (sub) systems of their own but of the target culture in any event (Toury, 1995, pp. 23-39). Equivalence becomes a descriptive, dynamic term. Features are retained and reconstructed in target language texts. Importance so assigned is to facilitate the audience only. Within the target oriented framework anything is included as a literary translation that is regarded, as such, by a certain 
cultural community at a certain time. Gideon Toury recommends investigating what translations are, rather than what they fail to be.

He speaks of translation norms at three levels, preliminary, initial and operational. Preliminary norms relate to textual issues like the position of translation within the polysystem of a target culture and option of languages and texts to be translated. The opposing poles of adequacy and acceptability constitute initial norms. According to Toury adherence to some text norms determines a translation adequacy as compared to the source text. Subscription to norms originating in the target culture determines its acceptability. At times a translated text need not be consistent in its adequacy and acceptability. Actual translations operate between these two poles (Ibid., 53-69).

As far as the two concepts adequacy and acceptability are concerned, criticisms poured in. Active translation critics as Gentzler and Hermans published their similar opposition (Genzler, 2001; Hermans, 1999). In the first place, on what grounds a translated text is judged adequate or acceptable? According to Toury, the source text must be brought into view and this necessitates a detailed macro plus micro comparison between the original and the translated. However, this approach works well out of his pure target-orientedness and stains his theoretical consistency. In the second, as translation is conventionally or traditionally understood, a translated text reads like either more foreign or more native, opting towards the SL or TL. A translated text always finds itself at some point on the continuum stretching from adequacy to acceptability. The above seriously stated claim is naturally reduced to a position of little significance. What is said ends up unsaid.

\subsection{Prescriptive Underpinnings of Toury's Kernel Concepts}

Toury intended to establish a set of consistent models within the systemic paradigm which stand potentially against the traditional translation theories. His theoretical development can be assessed through examining several key concepts he proposed and defended to construct a "general theory of translation". The key concepts exposed themselves as unexpectedly against his original intents and the symbolic D (description) of DTS is to be gravely questioned.

See the figure below:

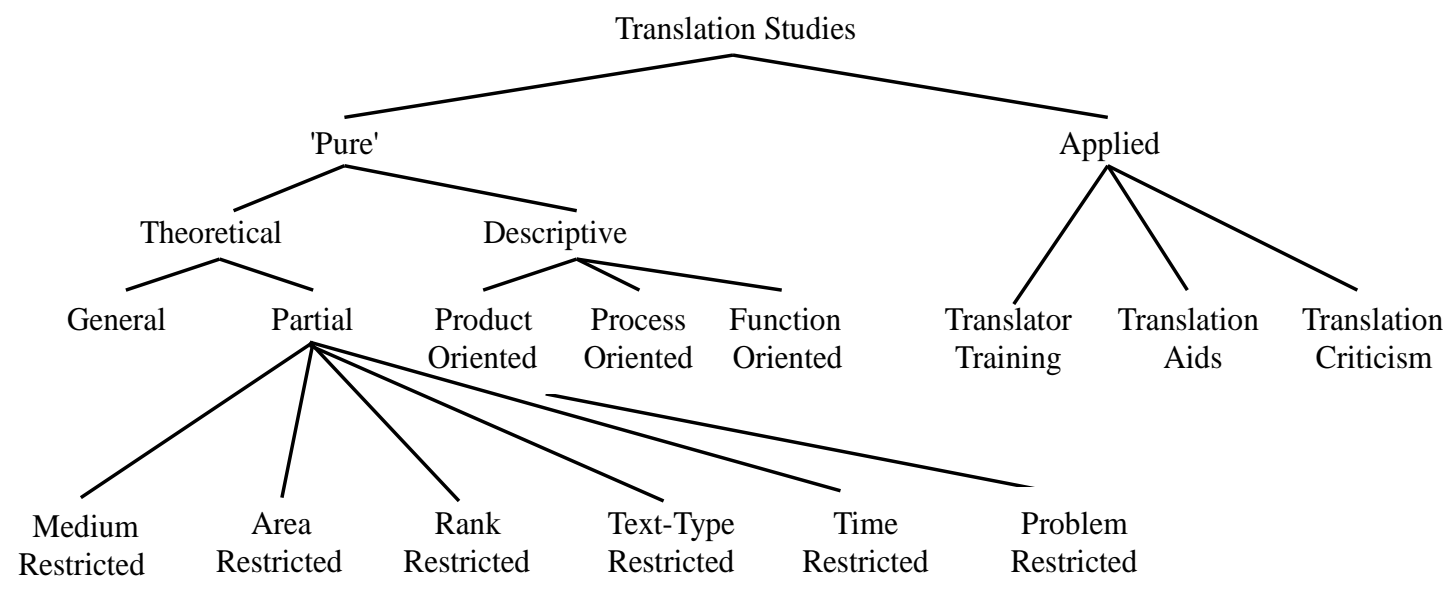

Figure 1. Holmes' conception of translation studies (Toury, 1991, p. 181)

In Homles' original paper, no figures of this type can be found. Toury's presentation intended to roughly embody the predecessor's thesis, but not genuinely. Mainly the "applied" branch was virtually elevated to an unexpected paralleled position to the "pure", a much higher position Holmes did not conceive at the very start. Holmes put emphasis on the "pure" branch, hence much larger space of the paper for it and further classifications and delimitations, comparing against the "applied" branch whose subcategories apeare somewhat pale and curtailed. This handling of the structure of the discipline corresponds with Holmes' own view of the purported goal of establishing such a scholarly research: “...translation studies thus has two main objectives: (1) to describe the phenomena of translating and translation(s) as they manifest themselves tn the world of our experience, and (2) to establish general principles by means of which these phenomena can be explained and predicted" (Liao, 2006, p. 54). The two objectves directly point to the Descriptive and the Theoretical respectively under the heading "pure". It seems that the "pure" has covered all that is essential to the discipline and the "applied" manifests 
itself as supplement of some kind at the most, very marginal to the dicspline proper. It may be argued that in applied areas many variants are still to be defined and translation practices across the centuries only prove to be atheoretical and unable to be depicted in any established paradigm, and as a result Holmes chose not to include the applied as an intrinsic component in the sense of the nature of the discipline "as a field of pure reseach".

Toury's interpretation runs counter to his own claim as well as Holmes' initial objectives:

To be sure, it has always been my conviction that it is no concern of a scientific discipline, not even in the so-called "sciences of man", to effect changes in the world of our experience...Strong as this conviction is, however, it does not preclude the possiblity of drawing conclusions from theoretical reasoning, or scientific findings, to actual behaviour, be its orientation retrospective or prospective. (Toury, 1995, p. 17)

He disagrees very much with Newmark's view on this issue: "translation theory's main concern is to determine appropriate translation methods" (Newmark, 1981, p. 19), but not to a point he found difficult to make his own theory applicable. His map-like presentation of Holmes' scheme explains why he raises the position of the applied branch and keeps theoretical application in mind in the course of the development of DTS. His ultimate "general theory" is to be borne out of the DTS and extended beyond the pure theoretical enquiries finally reaching the applied areas. Thus, it is best to include the applied branch and to keep its significance as great as needed just at the departure of DTS research. It is not rational to be required to engage in completely pure research regardless any real word relevance, nor is it rational to exclude the possibility of researchers hiding the true objectives.

\subsection{Translational Laws Concluding Toury's Journey to Prescription}

Toury's idea of norms in descriptive studies will enable, he thought, a formulation of laws of translation and thereby lead us to "universals of translation". The laws he proposes are: (1) The law of growing standardization, which states that textual relations of the original are ignored in favor of the options offered by the target language; (2) The law of interference. Interference here refers to the ST linguistic features being copied in the TT, which happens understandably when the translation is from a prestigious language or culture and the target language or culture is minor. (Gentzler, 2001; Hermans, 1999; Munday, 2001)

Toury favours the form of formulation of translation laws "if X, then the greater/the lesser the likelihood that Y" as the only "unmistakably" legitimate one while dismissing lists of possibilities and directives as unlawful (1995, pp. 159-165). Even though he took pains to designate probabilistic nature to his formulation of laws, it is pointless for translators to differentiate his from others and those guidelines in a translation teaching book. Even though he sees the importance of emphasizing "relations of variables", the mandatory and prescriptive nature of lawful statements has not yet been lessened anyhow. These laws are just what he had been seeking after all the way to abridge the theoretical enquiries and real-world translation practice. What he did earlier (his interpretation of Holmes' scheme and the suggestion of norms) all serves this purpose. The universality of applying the laws (though not enough laws can be formulated for the time being), he sees, promises to finalize a general theory of translation.

\section{Toury's Permutation from Description to Prescription}

The precriptiveness of Toury's models is not easy to discern, especially when one considers his main contribution to translation research, DTS. The use of the term "descriptive” can be very misleading. A translation researcher, when taking the influence of Russian Formalism into consideration, does not at all intend to yield to description. Toury wanted his models to be descriptive, objective and applicable, but he finally slipped into a trap he himself laid of appearing descriptive with prescription underlined.

\subsection{Toury's Deliberate Elevation of the Descriptive and Applied Branch}

Twenty-three years after Holmes had proposed the very first map of Translation Studies, Toury (1995, p. 18; see also the diagram above) put forward his vision of the organization of the discipline by means of a programmatic map which he adapted from Holmes'.

The first difference between the two views of the scope and structure of Translation Studies lies in the role ascribed to Descriptive Translation Studies. According to Holmes each of the three main branches of the discipline-Theoretical, Descriptive and Applied Translation Studies-plays an important role in the expansion and development of this new field of study. The relationship between Descriptive Translation Studies and the other two branches - the theoretical and the applied-is dialectical, and the development of the entire discipline is dependent on the harmonious and dynamic interaction of all three elements, each of which enjoy equal status. Toury, on the other hand, attributes to Descriptive Translation Studies a key role in the evolution of the entire discipline as an independent area of study. He argues that "no empirical science can make a claim for 
completeness and (relative) autonomy unless it has a proper descriptive branch” (Toury, 1995, p. 1).

Toury spells out in great detail the object of study of each of the three subdivisions of Descriptive Translation Studies and their interrelationship (product oriented, process oriented and function oriented). These three areas of Descriptive Translation Studies constitute a complex whole. For Toury, function is given a primary role over product and process. Holmes, however, saw function, product and process as having the same importance. For Toury, however, the ongoing activity of translating into Welsh, for example, novels, pieces of legislation, local government policies and regulations, plays a key role in the preservation of the Welsh language and culture in Wales in the United Kingdom. This function (of preserving the language), Toury argues, determines the actual textual make-up of the translation (the product) and reveals the process of translating. The aim of Toury's Descriptive Translation Studies as a whole is the relationships between the function and the product and process of translation.

The relationship between Descriptive Translation Studies and Theoretical Translation Studies is reciprocal. The results of descriptive research-which reveal what translation does involve and why - will always produce theoretical hypotheses about what translation can, in principle, involve. On the basis of this empirical foundation, the theory will then be in a position to predict what translation is likely to involve under various circumstances (1995, p. 15).

The applications of translation studies constitute, in Toury's map, a separate field of research which draws on a variety of disciplines, such as theories of teaching and learning, information technology, contrastive analysis, computational linguistics, etc. Toury's position is very different from Holmes' in this respect. Holmes viewed all branches of translation studies, including Applied Translation Studies, as interdependent and as enjoying equal status within the entire discipline, but Toury considers the practical concerns of translation teaching, translation criticism and translation aids as "tensions" of the discipline, therefore not at the core of Translation Studies, apparently lowering the position of the applied branch but virtually elevating it.

\subsection{Toury's Ultimate Goal}

The focus of discussing Toury's translation laws in this thesis is not on how the two laws were proposed by Toury and how they might operate, but on the thinking lines behind the proposition. Hermans sees three steps in Toury's reasoning which leads to the laws:

(1) we consider what, in theory, translation can involve; (2) then we compare this with what, under particular conditions, translation has apparently involved; (3) finally we deduce what, under conditions to be specified, translation will probably involve- - Equipped with the possible and the actual we project the probable”. (Hermans, 1999, p. 92, bold types added by the writer)

This line of thinking is logical in itself, but it only works on a concrete level. The basic theorizing must be found in Toury's formalist and systemic paradigms. Gentzler points out "Despite efforts to include differing socio-historical conditions, there is the underlying tendency throughout this 'historically determined' theory toward 'pure' formalism” (2001, p. 130). In keeping line with the goal of the polysystem theory, Toury's ultimate goal is to develop a general theory consisting of such laws, which he argues valid for all translational phenomena.

Introducing norms in translation studies serves just as a stepping stone to the more theory-like translation laws. Next and finally, Toury argues, it is mature to "move on to the formulation of general laws of translational behaviour":

To put it differently: the cumulative findings of descriptive studies should make it to possible to formulate a series of coherent laws which would state the inherent relations between all the variables found to be relevant to translation. Lying as it does beyond descriptive studies as such, the formulation of these laws may be taken to constitute the ultimate goal of the discipline in it theoretical facet. (1995, p. 16)

Even though only two laws were temporarily proposed for the purpose of exemplifying the "lawful" form of formulation of laws and testifying such laws do exist, Toury obviously takes an optimistic view of the prospect of discovering more laws and constructing a more "general" theory of translation.

\subsection{Toury's Theoretical Return to Prescription}

Gideon Toury's norms were supposed to be non-prescriptive, while all norms exert a prescriptive pressure. After he stipulated that translation laws must be advanced and the "correct" form of formulation of laws should be the $\mathrm{X}-\mathrm{Y}$ formula, his theory's prescriptiveness stands even more out. This is what the above discussion is aimed at. 
The following argumentation serving the same purpose of disclosing his prescriptiveness is set from a different perspective, namely, the dialectic relationships of prescription and description, theory and practice and other pairs of concepts traditionally assumed to be opposite.

It is not pointless to talk about the relationship between prescription and description as Toury's theory is deeply rooted in traditional paradigms and deeply influenced by prescriptive thinking. Through this discussion we can see more clearly the cause and effect, and the necessity of Toury's being prescriptive. This discussion is brief but revealing.

Whatever in China or abroad, prescriptive translation theory has been considered as an unshaken guiding principle, and this phenomenon continued till the 1950s. No one queried the validity of this statement. People believed that the function of the theory is the norm of action, which is right and proper to unite people's thinking. If there is no prescriptive norm, the translation republic would be in great disorder under heaven. However, an undisputed fact is that there has been a great disorder in translation, such as continuous and endless controversy on "word-for-word" and "sense-for-sense" debate, for on the key question "fidelity" no unanimousness can be drawn. Of course, the norms of prescriptive translation theory have its function, which tells us what target a translation should realize from critic's points of view. Its main drawbacks are in two aspects. One is that it always thinks that its norm is the only right one and applies it into all the translations. Nida's dynamic equivalence is a case in point, which defines the goal of dynamic equivalence as seeking "the closest natural equivalent to the source-language massage" and "aims at complete naturalness of expression" (Nida, 1964, p. 166; Nida \& Taber, 1969, p. 12). "Naturalness" is the key requirement for Nida. His success of the translation should depends on his requirement and achieve equivalent response. "It is one of the four basic requirements of a translation" (Munday, 2001, p. 42). On the other hand, it confined itself to language- the small field, and does not care for culture- the large environment. Although it has already referred to culture, the final purpose still remains on specific translation skills, overemphasized skills of translation. Perhaps this is the real reason why prescriptive translation theory cannot separate itself from the debate between "word-for-word" and "sense-for-sense".

What is descriptive translation theory? Maria Tymoczko said, "Descriptive translation studies—when they attend to process, product, and function - set translation practice in time and, thus by extension, in politics, ideology, economics, culture" (1999, p. 25). Descriptive translation theory is assumed to be the opposite of prescriptive translation theory. It displays great "tolerance”, just as Gideon Toury, the representative of descriptive school, pointed out, "A translation will be any target language text which is presented or regarded as such in a target system, on whatever Ground" (1980, pp. 22-39). If one can tell why it is translated like that, however ridiculous the reason is, the text can be considered as a translation. The interest of descriptive translation theory is not in language itself, and it tries to inquire into the translation origin and its social action. Meanwhile translation is restricted by a nation's norms of ethics and literature, revealing this relationship is also interested by descriptive translation theory. The scholars of descriptive school often ask two common questions: (1) Which factor causes translator to translate the text into another language? (2) What is the function of a version in the target language? There is an example to illustrate the point. The poem "When You Are Old" written by a contemporary British poet and dramatist has been translated into many versions. Prescriptive theorists analyze them from prescriptive angles, such as, which is "word-for-word" translation? Which is "sense-for-sense" translation? In contrast, descriptive theorists said that this was a very good phenomenon for a text having many versions .

Here it is not meant that prescriptive theory studies are not good, but that the studies are not so perfect. Translation studies should observe questions from microscopic angles. Prescriptive and descriptive translation theories are not contradictory, we'd better combine them together, and such translation studies can reveal complete translation. This is why Prof. Maria Tymoczko likened microscopic and macroscopic studies to microscope and telescope. Above all, descriptive translation studies not only can instruct translation practice and enrich translation approach, but also explain the orientation of all kinds of translations and help to deal with some knotty problems in translations. Thus it can be seen, the basis of translation norms is the descriptive for language reality, and its effect must be examined by language reality and development. In the final analysis, translation norms are not ossified or formulized theoretical concept and miraculous cure. In practice we should dexterously use translation theory and make them more perfect.

\section{Conclusion}

Toury's translation theory exposes its prescriptiveness by itself. Very popularly and successfully as the theory has long been received and cited since the 1980s, few ever questioned its legitimacy as positioned to be a theory qualitatively distinct from traditional theories and a theory claimed to be objective and descriptive. This theory's 
main force lies in the DTS, which initiated the following decade of descriptive work in translation studies in a cosmic way. However, the term description can be very deceptive if researched deep into it. Heavily influenced by the Russian Formalism and polysystem theory, Toury's theory was predestined to be prescriptive rather than descriptive. The prescriptiveness did not expose itself clearly until the laws were proposed. When closely examined, each of his key ideas speaks for its prescriptiveness. It is too simplistic to conclude that he himself did not anticipate the unfavorable aspect of his theory for he was never prepared to hide his true intentions. Much rewarding work has been encouraged by his theory, descriptive or prescriptive.

The discussion of Toury's prescriptiveness arouses the other discussion of re-evaluation of prescription, which necessitates the discussion of the relationships of translation theory and practice. Both discussions are essential in that some solutions should be arrived at to deal with currently emerging problems. The pace of translation theory development is fast and it is high time that we bravely confronted the seemingly unsolvable. In the author's view, prescription is just the sticking point. Past experiences tell us that prescription can do no more harm than is thought. If correctly handled, prescription can be very powerful and constructive. At least, it does exert its remarkable force against the maladies in teaching and studying translation theory.

\section{References}

About Translation. (n.d.). Retrieved April 28, 2014, from http://www.anukriti.net/translation3.asp

Catford, J. (1965). A Linguistic Theory of Translation. London: Oxford University Press.

Chesterman, A. (2000). A Causal Model for Translation Theories. In O. Maeve (Ed.), Intercultural Faultlines. Manchester: St. Jerome Publishing.

Even-Zohar, I. (1978). Papers in Historical Poetics. Tel Aviv: University Publishing Projects.

Gentzler, E. (2001). Contemporary Translation Theories (2nd ed.). Shanghai: Shanghai Foreign Language Education Press.

Hermans, T. (1985). Introduction: Translation Studies and a New Paradigm. In T. Hermans (Ed.), The Manipulation of Literature: Studies in Literary Translation. New York: St. Martins Press.

Hermans, T. (1999). Translation in System: Descriptive and System-Oriented Approaches Explained. Shanghai: Shanghai Foreign Language Education Press.

Hermans, T. (Ed.). (1985). The Manipulation of Literature: Studies in Literary Translation. New York: St. Martins Press.

Holmes, J. S. (1972). The Name and Nature of Translation Studies. Amsterdam: Rodopi.

Holmes, J. S. (1988). Translated! Papers on Literary Translation and Translation Studies. Amsterdam: Rodopi.

Holmes, J. S. (1989). Translating Martial and Vergil: Jacob Lowland among the Classics. In D. Weissbort (Ed.), Translating Poetry: The Double Labyrinth. Iowa City: Unversity of Iowa Press.

Jakobson, R. (1959). On Linguistic Aspects of Translation. In R. A. Brower (Ed.), On Translation. Cambridge, MA: Harvard University Press. http://dx.doi.org/10.4159/harvard.9780674731615.c18

Lefevere, A. (1990). Translation, Rewriting and the Manipulation of Literary Fame. London: Routledge.

Munday, J. (2001). Introducing translation Studies: theories and Applications. London: Rougledge.

Newmark, P. (1988). Approaches to Translation. New York etc.: Prentice-Hall.

Newmark, P. (2001). A Textbook of Translation. Shanghai: Shanghai Foreign Language Education Press.

Nida, E. A. (1964). Toward a Science of Translating: With Special Reference to Principles and Procedures Involved in Bible Translationg. Leiden: E. J. Brill.

Pym, A. (2003). On Toury's Laws of How Translators Translate. In A. Pym, M. Shlesinger, \& D. Simeoni (Eds.), Beyond Descriptive Translation Studies: Investigations in Homage to Gideon Toury. Amsterdam: John Benjamins Publishing Company.

Qiyi, L. (Ed.). (2006). Contemporary Translation Studies in the Western World. Chongqing: Sichuan International Studies University.

Snell-Hornby, M. (1988). Translation Studies: An Integrated Approach. Amsterdam: John Benjamins Publishing Company. http://dx.doi.org/10.1075/z.38

Steiner, G. (1998). After Babel: Aspects of Language and Translation. Oxford: Oxford University Press. 
Toury, G. (1980). In Search of a Theory of Translation. Tel Aviv: The Porter Institute for Poetics and Semiotics.

Toury, G. (1982). A Rationale for Descriptive Translation Studies. In A. Lefevere, \& K. D. Jackson (Eds.), The Art and Science of Translation. New York: St. Martins Press.

Toury, G. (1984). Translation, Literary Translation and Pseudotranslation. In E. S. Shaffer (Eds.), Comparative Criticism 6. Cambridge: Cambridge University Press.

Toury, G. (1986). Translation: A Cultural-Semiotic Perspective. In T. Sebeok, \& P. Bouissac (Eds.), Dictionary of Semiotics. New York/Amsterdam: Mouton de Gruyter.

Toury, G. (1991). What are Descriptive Studies in Translation Likely to Yield Apart from Isolated Description? In K. V. Leuven-Zwart, \& T. Naaijkens (Eds.), Translation Studies: The State of the Art. Amsterdam: Rodopi.

Toury, G. (1995). Descriptive Translation Studies and Beyond. Shanghai: Shanghai Foreign Language Education Press.

Tymoczko, M. (1999). Translation in a Postcolonial Context: Early Irish Literature in English translation. Manchester: St. Jerome.

Tynjanov, J. (1978). On Literary Evolution (C. A. Luplow, Trans.). In Readings in Russian Poetics: Formalist and Structuralist Views. Ann Harbor: Michigan Slavic Publications.

\section{Copyrights}

Copyright for this article is retained by the author(s), with first publication rights granted to the journal.

This is an open-access article distributed under the terms and conditions of the Creative Commons Attribution license (http://creativecommons.org/licenses/by/3.0/). 